\title{
BOBBIO NA HISTÓRIA DAS IDÉIAS DEMOCRÁTICAS*
}

Assis Brandão

Bobbio tem duas inserções fundamentais na teoria da democracia: uma, como teórico da democracia ética e participativa, em seu período acionista - em que pertencia ao Partido da Ação ${ }^{1}$, nos anos de 1940 do século passado - e outra, como teórico do procedimentalismo democrático, a partir de meados da década de 1950. Cada uma dessas formas particulares de concepção do regime democrático insere-se em tradições diferentes no âmbito da referida teoria. Nosso objetivo aqui é tentar perceber quais são essas tradições e o modo particular de inserção de ambas e as concepções do autor no interior delas.

\section{A democracia ética e participativa}

A democracia ética e participativa de Bobbio encontra-se no interior de duas tradições fundamentais da teoria democrática:

\footnotetext{
* Este artigo é uma versão ligeiramente modificada do Terceiro Capítulo de minha Tese de Doutorado, A concepção de democracia em Bobbio, defendida no Doutorado em Ciências Humanas: Sociologia e Política da UFMG, em 2001.

${ }^{1}$ O Partido da Ação é o partido do socialismo liberal/liberal socialismo italiano. Teve curta vida. Fundado em 1942, afirmou-se na luta para libertar a Itália do fascismo e dos invasores alemães, mas, após fragorosa derrota nas eleições constituintes de 1946, extinguiu-se, em 1947, integrando-se ao PSI. Por esse partido, Bobbio candidatou-se, e perdeu, a uma vaga na Assembléia Constituinte.
} 
a da democracia desenvolvimentista e a da democracia participativa. Remetendo-nos aos modelos de democracia delineados por Macpherson, em A democracia liberal, percebemos que a "democracia desenvolvimentista" surge historicamente após a "democracia protetora". Este modelo de democracia, constituído a partir da reflexão democrática de Jeremy Bentham e James Mill, acolhe, no fundamental, tanto o homem da sociedade capitalista como essa própria sociedade da maneira como eles são, sem a preocupação com o empreendimento de qualquer mudança em ambos. Com isso, a democracia protetora é vista como tendo por função tão-somente o estabelecimento de uma certa proteção dos cidadãos contra os governos. A idéia de Bentham é que, à exceção dos governantes dos regimes democráticos, todos os demais tendem a oprimir a cidadania. É inclusive com base na proteção dada pela democracia aos governados contra os governantes que o autor funda a sua justificação do referido regime.

124 A democracia protetora, no entanto, de acordo com Macpherson, a partir de meados do século XIX, passou a ser questionada por pensadores pertencentes ao próprio campo liberal. Segundo ele, duas mudanças ocorridas na sociedade capitalista chamaram a atenção de tais pensadores, levando-os a pleitear um novo modelo de democracia. Essas mudanças são as seguintes: 1. "a classe trabalhadora - que Bentham e James Mill não consideravam perigosa - começava a parecer perigosa à propriedade"; e 2. "as condições da classe trabalhadora se tornavam tão ostensivamente desumanas que os liberais mais sensíveis nem a podiam aceitar como moralmente defensável ou economicamente inevitável" (Macpherson, 1978: 49).

Surge, assim, a democracia desenvolvimentista. Sua principal diferença em relação à democracia protetora é que ela tem uma natureza ética, no sentido de manifestar uma certa preocupação com o desenvolvimento da humanidade. John Stuart Mill (1981: 19), seu mais destacado teóri- 
co, afirma, em Considerações sobre o governo representativo, que "o mais importante mérito que pode possuir uma forma de governo é o de promover a virtude e a inteligência do próprio povo". Inclusive, para ele, um dos critérios primordiais de avaliação de um governo é a medida em que ele tende a aumentar ou diminuir "a soma de boas qualidades dos governados, coletiva e individualmente".

Em relação à democracia, Mill (1981: 148) afirma que ela é o regime político que melhor possibilita a "educação pública dos cidadãos". Ao permitir a mais ampla participação da cidadania não apenas em processos eleitorais, mas também em alguns espaços da estrutura pública, como, por exemplo, os júris populares, a administração local etc., a democracia faculta aos cidadãos uma espécie de pedagogia política, fazendo-os desenvolver a amplitude dos seus raciocínios e pensar um pouco mais no "bem comum". Referindo-se, especificamente, à participação da classe trabalhadora em tal regime, Mill (1981: 88-89) observa que é "através da discussão política que o trabalhador manual, cujo emprego é uma rotina e cuja maneira de viver não o põe em contato com nenhuma variedade de impressões, circunstâncias ou idéias, aprende que causas remotas e acontecimentos em lugares distantes exercem uma influência imediata e sensível sobre seus interesses pessoais e reais; e é através da discussão política, e da ação política coletiva, que um homem, cujos interesses são limitados por suas ocupações diárias a um círculo estreito, aprende a simpatizar com seus concidadãos e se torna um membro consciente da grande comunidade”. É evidente, no entanto, que a educação pública da cidadania permitida pelo regime democrático, de acordo com o autor, não se restringe à classe trabalhadora, sendo ela genérica, de modo que alcança todos os setores da sociedade (Mill, 1981: 38).

O modelo de democracia desenvolvimentista criado por Mill, segundo Macpherson (1978: 53), é acolhido, com algumas modificações, por vários prestigiosos autores do 
mundo ocidental - tais como Hobhouse, Lindsay, Ernest Barker, Woodrow Wilson, John Dewey, MacIver etc. -, em que, ao que parece, até meados do século passado, quando do advento da concepção schumpeteriana de democracia, tornou-se o modelo de democracia hegemônico.

Bobbio, que só se torna procedimentalista na década de 1950, esgrime, em seu período acionista, uma concepção de democracia que é, também, desenvolvimentista. Para ele, a democracia tem um fim: a educação dos cidadãos para a liberdade. Ela ensina os cidadãos a serem livres. É essa preocupação com o desenvolvimento da cidadania, no sentido de educá-la para a liberdade, que, segundo ele, distingue o regime democrático de qualquer outra forma de governo (Bobbio, 1996a: 29). Ao mesmo tempo, é essa mesma preocupação que insere a concepção de democracia acionista do autor no âmbito do modelo desenvolvimentista de democracia.

Interessante é observarmos que os sentidos do apri126 moramento humano pleiteado pelos desenvolvimentismos democráticos de Mill e Bobbio são um tanto diferentes. Em Mill (1981: 19), ele se configura a partir do temor da manifestação de dois problemas que o autor qualifica como básicos para a não-ocorrência de um "bom governo": 1. Que os indivíduos atentem "apenas para aqueles de seus interesses que são egoístas"; e 2. que lhes falte inteligência. O governo democrático, pensado como "bom governo", levaria à superação de tais problemas. Os homens, que, em sua maioria, levam uma rotina centrada na busca da satisfação de suas necessidades diárias - o que, de certo modo, tolhe o desenvolvimento da sua capacidade de raciocínio e os torna muito autocentrados -, através da participação democrática, teriam, por um lado, possibilitada uma abertura para a realização de raciocínios mais amplos, aprimorando a sua capacidade intelectual, e, por outro, a oportunidade de refletir pelo ângulo de quem ocupa funções públicas, aprimorando sua capacidade de ação orientada pelo interesse coletivo. 
Em Bobbio, o sentido do referido aprimoramento é delineado, fundamentalmente, com base na percepção que o autor tem do homem sob o regime fascista. É verdade que nenhum regime ditatorial educa o homem para a liberdade. Todavia, indiscutivelmente, para ele, por essa perspectiva, o fascismo é emblemático. Mesmo sem referir-se explicitamente a esse regime, Bobbio (1996a: 29) evidencia que nele não é possibilitada aos homens a aquisição da consciência do seu valor enquanto tal e, assim, "das próprias possibilidades e dos próprios limites no mundo dos outros homens". Essa aquisição é que ele chama de educação para a liberdade. Apenas a democracia a possibilitaria. O homem livre é o homem consciente de suas possibilidades e de seus limites em sua relação com os outros. Para que essa consciência exista, é necessário, de acordo com o autor, que ocorra "um ambiente social cujas condições econômicas, políticas e culturais" favoreçam o seu desenvolvimento. (Bobbio, 1996a: 29) Tal ambiente, de certa forma, em sua opinião, pode ser criado pelas instituições democráticas.

Assim, enquanto em Mill o aprimoramento humano, na democracia, dá-se pela superação da ignorância e do autocentramento, no sentido da ampliação da capacidade de raciocínio dos indivíduos e do seu agir pautado pelo interesse coletivo, em Bobbio, diferentemente, ele ocorre pela superação da falta de consciência dos homens quanto às suas possibilidades e limites em sua relação com os outros, isto é, pela aquisição da sua liberdade. Segundo ele, só os homens livres são responsáveis enquanto cidadãos.

De qualquer maneira, os desenvolvimentismos de Mill e Bobbio são ambos participacionistas. É verdade que está fora do âmbito das nossas preocupações aqui o empreendimento de qualquer discussão mais acurada sobre a natureza da participação na democracia milleana, pois ela não é uma influência relevante no desenho de democracia participativa do Bobbio acionista. Destacamos apenas que as democra- 
cias participativas desses dois autores são, as duas, representativas. Todavia, enquanto a estrutura representativa de Mill se restringe ao próprio Estado, a de Bobbio envolve, para além do Estado, uma variada gama de instituições pertencentes à sociedade civil.

Bobbio mostra-se sobremodo enfático ao afirmar que a democracia defendida por ele não pode ser confundida quer com a democracia grega, quer com a rousseauniana. Isso, tanto no sentido de que elas são democracias diretas, e a democracia moderna, de maneira alguma, pode ser desprovida de representação, como também pelo fato de que, no registro bobbiano do imediato pós-guerra, tais democracias são carregadas de um certo teor totalitário. Segundo o autor, nelas há participação além do desejável, de modo que o indivíduo se encontra completamente absorvido pelo Estado. Essa visão de Bobbio, relativamente comum naqueles anos, reverbera a desconformidade dos democratas com 128 a forma de participação fascista, que marcava ainda fortemente as preocupações de todos.

Do ponto de vista da teoria da democracia, a conseqüência fundamental da leitura bobbiana das democracias grega e rousseauniana é um certo distanciamento de sua concepção de democracia participativa em relação à mais importante tradição desse tipo de democracia, que é a tradição da democracia direta, constituída precipuamente por elas. Não apenas porque ambas são diretas, mas, primordialmente, por serem excessivamente participativas e, assim, em sua opinião, prenhes de conteúdo totalitário.

Há algo em comum entre a reflexão democrática de Bobbio, em seu período acionista, e a reflexão do Marx democrata radical da Crítica da filosofia hegeliana do direito público. Nessa obra, Marx acolhe a idéia da ocorrência da separação entre o Estado e a sociedade civil e coloca como perspectiva a superação dessa sociedade. Bobbio, de maneira similar, também percebe tal separação e, como o filósofo 
alemão, pleiteia a sua extinção. No entanto, ambos apresentam propostas bastante distintas para a realização dos seus objetivos.

Marx rejeita a democracia direta, dando razão a Hegel, que não era democrata, para quem os grandes números são impeditivos à sua realização. E também não acolhe a democracia participativa. Ele parece restringir-se à proposição de que o fosso entre a sociedade civil e o Estado pode ser preenchido através da "eleição absoluta, tanto ativa quanto passiva", isto é, uma eleição em que todos votam e todos podem ser votados (Marx, 1987: 432). Nesse caso, tornando-se a sociedade civil a "sociedade política real", o poder legislativo perderia o seu caráter representativo, mas a democracia não se tornaria direta (Marx, 1987: 430). O referido poder teria os seus membros eleitos pela cidadania, mas, por agir genericamente, "enquanto todos", careceria de representação, mesmo que, por desempenhar uma função social como qualquer outra, não deixasse de ser representativo. "Aqui", diz Marx (1987: 430), o poder legislativo "é representante, não do outro a quem representa, senão do que ée do que faz".

Em Bobbio, o reencontro da sociedade civil com o Estado ocorre de maneira sobremodo mais avançada do que em Marx, através da democracia participativa. Essa democracia tem por pilares fundamentais a participação ativa da cidadania, o federalismo e a idéia de "democracia direta". Seguramente, ela também não é tributária do Marx democrata radical.

No entanto, a democracia participativa do Bobbio acionista, em consonância com o pensamento do autor no período, esteia-se tanto no socialismo como no liberalismo. É nessas duas tradições de pensamento que se coloca o participacionismo bobbiano. Na realidade, ao que parece, o liberalismo, exceto em momentos mais ou menos raros, ou excepcionalmente, nunca apresentou maiores afinidades com o participacionismo. Todavia, ele foi quase sempre descentralizador. Bobbio, em seu caminho para a defesa da 
democracia participativa, inspira-se, de alguma forma, no liberalismo. O federalismo de Cattaneo ${ }^{2}$ é, indiscutivelmente, uma teoria liberal. Estritamente liberal, posto que não democrática. Cattaneo, inclusive, nunca foi um democrata. Ao contrário, sempre se insurgiu contra a idéia do sufrágio universal. O seu federalismo funda-se, precipuamente, na descentralização política. Segundo Bobbio, para ele, "os gânglios vitais da futura república federal italiana (deveriam) ser os municípios”. O conjunto de municípios - as "republiquetas" -, formariam a grande república - a "republicona" -, chamada por ele de "Estados Unidos da Itália". (Bobbio, 1971: 32)

Porém, o referido federalismo, mesmo sendo liberal, é também participativo. Nele, de acordo com Bobbio (1971: 54-55), "existem todos os pressupostos para um avanço democrático dos Estados mais do que na teoria do sufrágio universal, [pois] [...] o sufrágio universal é um expediente, não é 130 o princípio, da democracia, a qual progride não tanto em proporção ao estender-se meramente quantitativo do sufrágio, quanto proporcionalmente ao multiplicar-se das instituições de autogoverno”. A descentralização estatal, pleiteada pelo federalismo cattaneano, na medida em que acolhe a autonomia municipal, mesmo não o fazendo de maneira democrática, uma vez que não acolhe o sufrágio universal e sim a descentralização política, coloca em perspectiva, segundo Bobbio (1971: 54), a possibilidade de encaminhar-se "na direção de uma genuína democracia, posto que esta multiplicidade dos centros autônomos pressupõe e promove uma maior participação dos cidadãos na coisa pública”.

2. Cattaneo foi um escritor liberal italiano, do século XIX, que defendeu o federalismo como forma de descentralização política. Bobbio o teve como um dos seus cinco grandes autores "contemporâneos", ao lado de Croce, Kelsen, Pareto e Weber. 
A idéia de que o federalismo liberal de Cattaneo era participativo é evidenciada por Bobbio (1996a: 104), de maneira ainda mais clara, por exemplo, quando ele afirma que, ao definir o federalismo como uma "teoria da liberdade", tal autor "entendia por liberdade o exercício do poder de baixo, a prática do autogoverno". Ou ainda, quando ele sugere que, no final da quinta década do século XIX, Cattaneo já via a federação como "aquela forma de Estado que garante, melhor do que qualquer outra, a liberdade dos cidadãos, assegurando-lhes uma mais ampla e direta participação no poder" (Bobbio, 1996a: 17).

Observamos que o federalismo de Cattaneo é pensado como ocorrendo no âmbito estrito do Estado. O de Bobbio, diferentemente, envolve não apenas o Estado como também a sociedade civil. Em Cattaneo, o núcleo do federalismo é o princípio liberal da descentralização estatal em comunhão com a idéia de uma certa participação da cidadania nas estruturas estatais descentralizadas. Em Bobbio, ele envolve a parte federalística da reflexão de Cattaneo, mas avança no sentido de acolher a participação da cidadania também nas instituições da sociedade civil. É verdade que, no que diz respeito à participação nas estruturas estatais descentralizadas, Bobbio a percebe como ocorrendo em níveis mais amplos do que Cattaneo, que, inclusive, não acolhe o sufrágio universal.

De qualquer maneira, o participacionismo do Bobbio acionista é influenciado diretamente por Cattaneo. Não apenas o estatal. Há uma passagem em Stati Uniti D’Italia, em que ele afirma que "mesmo no que respeita ao problema da transformação da sociedade, e não apenas do Estado, podemos hoje nos servir e estamos nos servindo" do federalismo liberal (Bobbio, 1971: 55). É certo que não era posto para Cattaneo o problema da participação da cidadania nas instituições da sociedade civil. Essa é uma preocupação de Bobbio (1971: 55), para quem o federalismo é "uma teoria 
da liberdade e da democracia". Contudo, de alguma forma, é como se Bobbio realizasse uma espécie de paralelo entre o autogoverno em estruturas estatais descentralizadas, algo presente em Cattaneo, e o autogoverno das instituições da sociedade civil. É a possibilidade teórica desse paralelo que o leva ao reconhecimento da contribuição de Cattaneo também em relação à participação da cidadania nas instituições da sociedade civil.

$\mathrm{Na}$ realidade, Bobbio transforma o federalismo liberalparticipacionista cattaneano em um federalismo democrático-participacionista. Para isso, ele, que acolhe o sufrágio universal, amplia a participação da cidadania na estrutura estatal descentralizada e a leva às instituições da sociedade civil.

Assim, talvez não seja exagerada a observação de que o participacionismo da democracia acionista de Bobbio poderia ser explicado, em grande medida, apenas através do recurso ao federalismo liberal cattaneano. Por esse ângulo, 132 a dívida bobbiana para com Cattaneo - que é um dos seus autores - é imensa.

Sendo isso correto, a democracia participativa bobbiana estaria fora das tradições fundamentais do participacionismo democrático, vinculando-se diretamente, em termos de ascendência, ao liberal-participacionismo cattaneano. Ela seria uma espécie de filha única do federalismo liberal.

A nosso ver, tais considerações, no fundamental, são verazes. Todavia, um tanto unilaterais, posto que a democracia participativa bobbiana é tributária também do pensamento socialista. Sbarberi (1994: 20), por exemplo, afirma que nela há uma certa influência da "idéia fabiana sobre a descentralização funcional da sociedade civil”. Os fabianos pleiteavam a constituição de um socialismo a partir, prioritariamente, dos municípios, com base na municipalização ou regionalização de empresas, serviços etc. (Cole, 1959: 119-121). Essas estruturas descentralizadas seriam perpassadas pelo processo democrático, o que significa a realização 
de seu "controle administrativo por representantes do povo livremente eleitos", posto que, mesmo defendendo o fortalecimento do poder local, eles eram contrários à democracia direta (Beer, 1948: 184).

Se dermos razão a Sbarberi - e somos propensos a fazê-lo-, o sentimento descentralizador de Bobbio seria tributário da influência tanto da descentralização liberal de Cattaneo como daquela socialista dos fabianos. Bobbio, no entanto, é mais cattaneano do que fabiano, pois, mesmo sendo um socialista, não vemos em seu pensamento nenhuma pista no sentido do acolhimento da idéia fabiana de transformar empresas e serviços em algo pertencente ao poder público local ou regional. O que ele pretende é o estabelecimento do município como locus democrático privilegiado da estrutura pública e a democratização das instituições da sociedade civil. Nessa dimensão, ele comunga, de maneira mais ou menos genérica, com a descentralização de Cattaneo e dos fabianos, mas vai além de Cattaneo, por pleitear o avanço da democracia também para as instituições da sociedade civil, e distingue-se dos fabianos, por não propor a apropriação de empresas e serviços pelos estados e municípios, propugnando, todavia, a sua democratização interna, o que, no limite, termina por significar, também, a sua descentralização, mesmo que não a sua publicização, no sentido de apropriação por qualquer dos níveis do poder estatal.

A influência do socialismo sobre a democracia participativa bobbiana não se restringe, entretanto, à descentralização. Ela faz-se presente igualmente no seu participacionismo. Por esse ângulo, provavelmente ela não provenha dos fabianos, para quem o processo de democratização das estruturas descentralizadas se expressa como mais representativo do que participativo, diferentemente do de Bobbio, que, malgrado a sua natureza representativa, é primordialmente participativo. Talvez uma observação de Perry Anderson sobre a crítica socialista, realizada por Bobbio à 
democracia representativa na década de 1970, possa lançar um pouco de luz sobre essa questão. Ele afirma que o autor italiano, "em nome de uma concepção de emancipação humana - e não apenas política - derivada de Marx, identifica todas as áreas de poder autocrático nas sociedades capitalistas que o estado representativo deixa completamente intocadas, privando-se a si mesmo, desse modo, das únicas bases sociais que haveriam de transformá-lo numa autêntica soberania popular" (Anderson, 1989: 34). Interessante é que, na década de 1940, quando da reconstrução do Estado democrático italiano, Bobbio, segundo Tommaso Greco (1996: 142), pleiteia uma "reconstrução que, para superar a desumanização da época dos totalitarismos, devia objetivar a humanização integral da vida social, do Estado e do ordenamento jurídico". Assim, tanto o Bobbio da década de 1970 quanto o da década de 1940 pleiteiam uma certa humanização da sociedade. Um, através da expansão da

134 democracia procedimental, e outro, através da democracia ética expandida.

Somos levados a acreditar que, mesmo o Bobbio acionista, ao propugnar a expansão da democracia do Estado para a sociedade civil, com ampla participação política em ambas essas seções da sociedade, já expressava uma certa influência do jovem Marx, posterior ao da Crítica da Filosofia Hegeliana do Direito Público, no que diz respeito à sua preocupação com uma maior autonomia dos indivíduos nas instituições e processos sociais.

A democracia participativa do Bobbio acionista, assim, é uma construção tipicamente bobbiana, mesmo que tributária, por um lado, e principalmente, do federalismo liberalparticipacionista de Cattaneo e, por outro, do socialismo. Do ponto de vista da descentralização, de maneira mais ou menos explícita, do socialismo fabiano, e, do ponto de vista da participação, mais ou menos implícita, do socialismo do jovem Marx. 


\section{A democracia procedimental}

O procedimentalismo democrático de Bobbio tem uma fonte bem conhecida: Kelsen. Como vimos, é ao Kelsen de Essência e valor da democracia, de 1929, que Bobbio atribui, originariamente, seu acolhimento da concepção procedimental de democracia.

Kelsen, na citada obra, antecipa muitas das idéias que Schumpeter desenvolveria, posteriormente, em Capitalismo, socialismo e democracia, de 1942. É verdade que não consta, no "índice remissivo" desse livro, o nome de Kelsen, o que nos leva ao entendimento de que talvez o economista austríaco não conhecesse a obra do professor da Universidade de Viena, pelo menos, não Essência e valor da democracia.

A concepção procedimental de democracia do Kelsen do entreguerras tem por núcleo a idéia de que a democracia é um método para a seleção de "chefes". O autor concebe que, em termos ideais, a democracia seria uma "coletividade sem chefes", algo assim no estilo rousseauniano. No entanto, segundo ele, "a realidade social de fato é o domínio, a existência de chefes” (Kelsen, 1993a: 88). Em razão disso, salienta que "a criação desses [...] chefes [é] o problema central da democracia real” (Kelsen, 1993a: 91). Para criá-los, todavia, é necessário um método, "um método específico de seleção dos governantes pela coletividade dos governados", algo que, em sua opinião, "aparece como elemento essencial" da referida democracia. "Esse método", diz ele, "é a eleição" (Kelsen, 1993a: 91).

Kelsen não entra em detalhes sobre o modo e as condições de realização dessa eleição. Evidencia, porém, algumas poucas características. Uma primeira, que esse método envolve a luta competitiva pelo poder. De acordo com ele, "o método da democracia [...] coloca a luta pelo poder sobre as mais amplas bases, tornando-a objeto de uma concorrência pública” (Kelsen, 1993a: 96). Uma outra, que essa 
concorrência se dá em condições em que são garantidos os direitos e liberdades individuais para todos. Por fim, que a minoria - que tem os seus direitos garantidos - possa ter a possibilidade de "tornar-se maioria a qualquer momento". (Kelsen, 1993a: 106)

Essas são umas poucas indicações que, não obstante o seu caráter rarefeito, contribuem para dar maior densidade aos delineios do método democrático kelseniano. Em primeiro lugar, por chamar a atenção para sua natureza competitiva e, em segundo, por incorporar, em sua própria estrutura, o patrimônio dos direitos liberais clássicos. Ele expõe-se, assim, como concorrencial e prenhe de conteúdos.

O procedimentalismo embrionário do Bobbio de Politica e cultura é visceralmente kelseniano. É kelseniana sua concepção de direito, a partir da qual chega à concepção de democracia, concebendo ambos - direito e democracia - como técnicas constituídas por normas; e é kelseniana 136 sua idéia de que a democracia é o "Estado fundado sobre a técnica do consentimento”. Interessante, no entanto, é que Bobbio não se refere à proveniência desse consentimento. Subentende-se que ele tem origem eleitoral, posto que se trata de uma liberal-democracia clássica. Porém, não há, no autor, referência explícita a eleições, como em Kelsen. Da mesma forma - e até por conseqüência -, também não há nenhuma alusão à luta competitiva pela liderança, algo também presente no professor da Universidade de Viena.

De qualquer maneira, o procedimentalismo bobbiano, como o de Kelsen, é conteudístico, pois a liberal-democracia, que, para ele, é a única forma de democracia moderna, já traz, em sua própria estrutura, normas cuja finalidade é o acolhimento dos direitos de liberdade clássicos, civis e políticos.

O método democrático schumpeteriano, ao que nos parece, apresenta fortes traços de aproximação com o do Kelsen de Essência e valor da democracia, mesmo sem o conhe- 
cimento - ou o reconhecimento - de Schumpeter. Essencialmente, ambos envolvem uma luta competitiva para a escolha das lideranças políticas. É verdade que o método kelseniano, comparado com o de Schumpeter, mostra-se relativamente tosco, algo rudimentar. De todo modo, o campo de confluência entre eles é bastante grande. Há, entretanto, pelo ângulo que nos interessa, pelo menos uma grande diferença. Referimo-nos ao fato de que a estrutura conteudística do método kelseniano é mais desenvolvida do que aquela do de Schumpeter. No método kelseniano, a incorporação dos valores liberais é sobremodo explícita. O mesmo, no entanto, não acontece no schumpeteriano. Schumpeter mostra-se um tanto reticente nesse campo. Por um lado, ao expor o que chama de "uma experiência mental”, convida-nos para que nos transportemos "para um país hipotético que, de maneira democrática, pratique a perseguição aos cristãos, a cremação de feiticeiras e o massacre dos judeus" (Schumpeter, 1961: 295). Com isso, rigorosamente, ao entender como possível a negação democrática de alguns valores liberais fundamentais, estabelece uma clara separação entre método democrático e liberalismo político. Ao mesmo tempo, ao apresentar "mais uma teoria de democracia", apesar de ainda com evidente hesitação, tenta estabelecer um certo vínculo entre ambos. Ele afirma que "se, pelo menos por questão de princípios, todos forem livres para concorrer à liderança política apresentando-se ao eleitorado, isso trará, na maioria dos casos, embora não em todos, uma considerável margem de liberdade de expressão para todos" (Schumpeter, 1961: 330). Malgrado o esforço do autor, tal vínculo afigura-se-nos como sobremaneira tênue, o que nos leva à idéia de que o método democrático schumpeteriano é quase somente democrático, sendo apenas tangencialmente também liberal. Assim, do ponto de vista do conteúdo, ele é mais estreito do que o de Kelsen, que é, de forma não-embuçada, democrático e liberal. 
Se a concepção procedimental de democracia de Kelsen encontra-se, em Essência e valor da democracia, ainda relativamente pouco desenvolvida, em Fundamentos da democracia, ela ganha contornos mais definitivos e, em alguns aspectos, um tanto distintos. $\mathrm{O}$ caráter parcialmente distintivo entre essas duas obras talvez nos permita a afirmação de que o Kelsen de Essência e valor da democracia, de 1929, é mais schumpeteriano do que o Kelsen de Fundamentos da democracia, de 1955-1956.

Na primeira dessas obras, o autor afirma que o "elemento essencial" da democracia é a eleição de chefes; na última, isso muda, de tal sorte que, segundo ele, "o critério fundamental da democracia é o de que o poder do governo reside no povo" (Kelsen, 1993b: 279). Passa-se do entendimento da democracia como método de eleição de chefes para o entendimento de governo do povo. Fazendo uma crítica direta a Schumpeter, mas, ao mesmo tempo, uma 138 espécie de autocrítica implícita, Kelsen (1993b: 280) salienta que "a eleição livre e sua conseqüência, a luta competitiva pelo voto popular, é um critério secundário” da democracia, sendo o seu critério essencial à idéia de que ela é um governo do povo.

Isso não significa, entretanto, que, em Fundamentos da democracia, o autor esteja abandonando sua visão de democracia como método. Ele a define como governo do povo, mas, simultaneamente, a acolhe como um procedimento. Para que o governo possa ser do povo, é necessário que este participe dele. Nesse caso, a participação pode ser direta ou indireta, com a configuração, respectivamente, da democracia direta ou da representativa. A essência da democracia, assim, é o governo do povo; sua forma é o modo através do qual o povo governa. As formas - democracia direta ou democracia representativa - seriam os métodos para a expressão da essência democrática - o governo do povo (Kelsen, 1993b: 142). 
Do ponto de vista da participação política, há também uma certa divergência entre Kelsen e Schumpeter. Ao definir a democracia como governo do povo, Kelsen enfatiza a necessidade da participação popular, direta ou indireta, no governo. É certo que isso não o transforma em um participacionista. De qualquer maneira, estabelece um certo vínculo entre a democracia e a participação, destacando a indissociabilidade entre ambas. Schumpeter (1961: 346), diferentemente, ao definir a democracia como "a concorrência livre entre possíveis líderes pelo voto do eleitorado”, nega o seu entendimento como governo do povo, acolhendo a idéia de "governo dos políticos". Nessa democracia, ao cidadão comum é destinada tão-somente a função de eleger os líderes. "Uma vez tendo eleito determinado cidadão", diz o autor, "a ação política passa a ser dele e não sua" (Schumpeter, 1961: 357). A apologia da não-participação da cidadania, em Schumpeter (1961: 358), chega a extremos tais que ele justifica até mesmo a proibição do envio de cartas e telegramas para as lideranças políticas a fim de evitar que a pressão da cidadania sobre elas venha a acarretar a restrição da sua liberdade de ação.

Por fim, em Fundamentos da democracia, Kelsen critica ainda Schumpeter pela dificuldade de sua concepção democrática com o liberalismo político. Também nessa obra, o procedimentalismo do professor da Universidade de Viena mostra-se mais conteudístico do que o do economista austríaco. Segundo Kelsen, Schumpeter afirma que "o método democrático não garante, necessariamente, uma liberdade individual maior do que o permitiria outro sistema político nas mesmas circunstâncias"; e, principalmente, que a democracia não pode "salvaguardar, em todas as circunstâncias, melhor que a autocracia, a liberdade de consciência" (Apud Kelsen, 1993b: 143-144). Ele discorda dessa postura schumpeteriana, dizendo que "se definirmos a democracia como um sistema político através do qual a ordem social é 
criada e aplicada pelos que estão sujeitos à ordem, de tal modo que a liberdade política, no sentido de autodeterminação, esteja assegurada, então a democracia, necessariamente, em todas as circunstâncias e em toda parte, estará a serviço desse ideal de liberdade política. E se, em nossa definição, incluirmos a idéia de que, para ser democrática, a ordem social, criada do modo como acabamos de indicar, deve garantir certas liberdades intelectuais, como a liberdade de consciência, liberdade de imprensa etc., então a democracia, necessariamente, em todas as circunstâncias e em toda parte, também estará a serviço desse ideal de liberdade intelectual" (Kelsen, 1993b: 144). E quando isso não acontecer, não existirá democracia. Essa postura kelseniana termina por introduzir mais valores na estrutura do seu método democrático do que aqueles que são acolhidos pelo método schumpeteriano.

O procedimentalismo democrático bobbiano apóia-se 140 tanto em Schumpeter quanto em Kelsen, mas, precipuamente, neste último. Bobbio é mais kelseniano do que schumpeteriano, mesmo que, de alguma forma, sofra a influência também do schumpeterianismo. De Kelsen, ele acolhe a própria idéia da democracia como método e a sua amplitude conteudística. $\mathrm{O}$ método democrático bobbiano, repercutindo a tradição kelseniana, foi sempre liberal e democrático, isto é, acolheu, em sua estrutura, valores democráticos e liberais. Como vimos, a incorporação do liberalismo político no método schumpeteriano dá-se de forma hesitante e um tanto insegura e, em alguns momentos, parece nem mesmo ocorrer.

De Schumpeter, Bobbio acolhe fundamentalmente o problema relativo à forma competitiva de seleção das lideranças políticas. É verdade que Kelsen, no entreguerras, já tinha levantado essa questão. Nele, a competição surgia como uma conseqüência de eleições livres. Em Schumpeter, a luta competitiva pela liderança ganha uma dimensão dife- 
renciada: é o próprio cerne de seu método democrático. Bobbio, apesar de esposar uma visão de procedimentalismo democrático mais abrangente do que a de Schumpeter, não deixa de acolher, schumpeterianamente, a existência da luta competitiva pela liderança política como uma conditio sine qua non da própria democracia. Pensamos, todavia, que Danilo Zolo (1992: 101) tem razão ao afirmar que a competição se apresenta, no método bobbiano, de maneira um tanto diferenciada - envolvendo um certo acréscimo - quando comparada ao schumpeteriano. Neste, a estrutura de competição entre as elites deve assegurar apenas a liberdade de escolha dos cidadãos, enquanto no bobbiano, para além dessa liberdade de escolha, é exigida também a ocorrência de uma multiplicidade de alternativas políticas, no sentido de mais de uma proposta política, entre as quais a de que os cidadãos possam exercer a citada liberdade.

Vemos, assim, que a concepção procedimental de democracia de Bobbio é tributária tanto do procedimentalismo de Kelsen quanto do de Schumpeter. Interessante, no entanto, é que via esses dois autores não é possível o entendimento da relação existente, em Bobbio, entre democracia e participação. Em alguns momentos da trajetória de seu procedimentalismo - que apresenta alguns vaivéns -, essa relação se aproximaria mais da visão schumpeteriana, com um certo acolhimento da apatia política; em outros, da kelseniana, com a percepção da necessidade de alguma participação. Todavia, tentar explicar a referida relação apenas através de Schumpeter e Kelsen é simplificá-la demasiadamente, colocando-a numa espécie de "leito de Procusto".

Por um lado, na vertente elitista - que justifica a apatia política -, para além de Schumpeter, Bobbio se apóia tanto nos elitistas não-democráticos, como Mosca e Pareto, quanto nos seus sucessores italianos que tentaram realizar o casamento entre o elitismo e a democracia, como, por exemplo, Dorso e Burzio. Por outro lado, na vertente mais 
participativa, para além de Kelsen, com sua justificativa de uma participação relativamente moderada, há toda a influência participativa de uma certa tradição socialista, da qual não está ausente, inclusive, o próprio Marx.

Observamos que, em perspectiva histórica, a influência do elitismo e da participação no procedimentalismo bobbiano se expressa, ao longo das décadas, como numa espécie de gangorra, de tal sorte que, quando a influência do elitismo sobe, a da participação desce, e a recíproca é verdadeira. O que não significa dizer, entretanto, que tal mudança de posição tenha ocorrido em todas as décadas - o que não seria correto -, posto que, por exemplo, o procedimentalismo das décadas de 1950 e de 1960 - décadas consecutivas - foi, em ambos os casos, não-participativo. Já na década de 1970, foi participativo e, na de 1980, apesar de relativamente participativo, termina por - em comunhão e contraditoriamente com essa vertente participativa - reali142 zar algumas racionalizações da apatia política.

Se tomarmos a relação democracia e participação, em Bobbio, com o objetivo de abranger toda a reflexão democrática do autor, teremos um quadro mais ou menos assim: 1. década de 1940 - ampla participação da cidadania; 2. década de 1950 - pouca participação política; 3. década de 1960 - pouca participação política; 4. década de 1970 - novamente ampla participação da cidadania, mesmo que não tanto quanto na década de 1940; 5. década de 1980 - relativamente ampla participação da cidadania, mas, na primeira metade dessa década, perpassada por raciocínios que, de uma ou outra maneira, racionalizam a apatia política. Na segunda metade, quando já não mais havia racionalizações da apatia, a ênfase participativa, de qualquer maneira, não voltou aos patamares da década de 1970, fundamentalmente em razão de o autor ter mudado a ênfase na sua percepção sobre a finalidade das "regras do jogo" democrático, que, antes, era essencialmente centrada na 
idéia da permissão de uma ampla participação da cidadania e, agora, na resolução pacífica dos conflitos; 6. década de 1990 - mais ou menos o mesmo sentido da participação da segunda metade da década anterior ${ }^{3}$.

Quando Bobbio define a democracia como um conjunto de regras cuja propriedade principal é permitir a maior participação possível - direta ou indireta - dos cidadãos nas decisões a que são submetidos, segundo Meaglia, ele está sendo kelseniano; quando, diferentemente, a define como um conjunto de regras cuja propriedade principal é a resolução pacífica dos conflitos político-sociais, de acordo com o mesmo autor, ele está sendo popperiano e kelseniano ao mesmo tempo. Em ambos os casos, Meaglia tem razão.

Em relação ao primeiro, Kelsen, em Fundamentos da democracia, defende a democracia como um "governo do povo" ou - o que não é senão uma maneira de dizer a mesma coisa com outras palavras - como "autonomia". Para que o povo seja autônomo, isto é, obedeça apenas às leis que ele próprio faz, é necessária a sua participação no governo, a qual, segundo o autor, pode ocorrer de forma direta ou indireta. A participação direta ou a indireta são métodos alternativos de concretização da autonomia popular, quer dizer, da democracia (Kelsen, 1993b: 142). Em Bobbio, isso é também assim. Com a diferença de que ele estabelece quais são as regras que regulamentam a referida participação.

Quanto ao segundo, a influência sobre Bobbio provém tanto de Popper quanto de Kelsen. De Popper, da sua conhecida definição de democracia "como a forma de governo caracterizada por um conjunto de regras que permitem a mudança dos governantes sem necessidade de usar a violência" (Bobbio, 1996b: 233). De Kelsen, da sua visão de que "o

3. A discussão sobre o pensamento democrático de Bobbio, ao longo do século passado - desde a década de 1940 até a de 1990 -, encontra-se, em detalhes, na minha tese de doutoramento. 
que caracteriza a democracia são as regras que possibilitam a livre e pacífica convivência dos indivíduos numa sociedade" (Bobbio, 1998: 82). Salientamos que Meaglia (1994: 17) chama a atenção para o fato de que Bobbio se remetia apenas a Popper quando diante da necessidade de reconhecer alguma ascendência para a sua idéia das regras configurativas da democracia como permissoras da resolução dos conflitos sem o recurso à violência. Posteriormente, no entanto, em sua autobiografia, Bobbio veio a reconhecer que essa sua concepção é tributária, também, de Kelsen, máxime do Kelsen de Essência e valor da democracia.

\section{Assis Brandão}

é professor de Teoria Política da Pós-Graduação em Ciência Política da Universidade Federal de Pernambuco - UFPE

\section{Bibliografia}

ANDERSON, Perry. 1989. "As afinidades de Norberto Bobbio". Novos Estudos CEBRAP, n. 24, pp. 14-41.

BEER, M. 1948. A history of british socialism. Londres: George Allen Unwin LTD.

BOBBI0, Norberto. 1971. Una filosofia militante. Studi su Carlo Cattaneo. Turim: Einaudi. . 1996a. Tra due repubbliche. Roma: Donzelli.

. 1996b. "Democracia”. In: SANTILLÁN, José Fernández (org.). Norberto Bobbio: el filósofo y la política. México: Fondo de Cultura Económica. pp. 229-238.

1998. Diário de um século. Autobiografia. Rio de Janeiro:

\section{Campus.}

COLE, G. D. H. 1959. História del pensamiento socialista. V. 3. La Segunda Internacional - 1889-1914. México: Fondo de Cultura Económica.

GRECO, Tommaso. 1996. "Appendice”. In: BOBBIO, Norberto. Tra due repubbliche. Roma: Donzelli. pp. 141-151.

KELSEN, Hans. 1993a. "Essência e valor da democracia". In: KELSEN, Hans. A democracia. São Paulo: Martins Fontes. pp. 23-107. 
. 1993b. "Fundamentos da democracia". In: KELSEN, Hans. A democracia. São Paulo: Martins Fontes. pp. 137-297.

MACPHERSON. 1978. C. B. A democracia liberal. Rio de janeiro: Zahar. MARX, Carlos. 1987. "Crítica del derecho del Estado de Hegel". In: MARX, Carlos; ENGELS, Federico. Obras fundamentales. V. 1. Marx - Escritos de Juventud. Mexico: Fondo de Cultura Económica.

MEAGLIA, Piero. 1994. Bobbio e la democrazia - Le regole del gioco. San Domenico di Fiesole: Edizioni Cultura della Pace.

MILL, John Stuart. 1981.Considerações sobre o governo representativo. Brasília: Editora da Universidade de Brasília.

SBARBERI, Franco. 1994. "Liberté et égalité - La formation de la théorie démocratique chez Bobbio". Archives de Philosophie, n. 57, pp. 3-31.

SCHUMPETER, Joseph A. 1961. Capitalismo, socialismo e democracia. Rio de Janeiro: Fundo de Cultura.

ZOLO, Danilo. 1992. Democracy and complexity. A realist approach. Cambridge: Polity Press. 


\section{BOBBIO NA HISTÓRIA DAS IDÉIAS DEMOCRÁTICAS}

ASSIS BRANDÃO

Norberto Bobbio tem duas inserções fundamentais na teoria da democracia. Uma como teórico da democracia ética e participativa, em seu período acionista - em que pertencia ao Partido da Ação, nos anos 40 do século passado; e outra, como teórico do procedimentalismo democrático, a partir de meados da década de 1950. Cada uma dessas formas particulares de concepção do regime democrático inse- 
re-se em tradições diferentes no âmbito da referida teoria. Este artigo tenta mostrar quais são essas tradições e o modo particular de inserção de ambas as concepções do autor no interior das mesmas.

Palavras-chave: Norberto Bobbio; Tradições Democráticas; Democracia Ética; Democracia Procedimental.

\section{BOBBIO IN THE HISTORY OF DEMOCRATIC IDEAS}

Norberto Bobbio has two fundamental insertions in democratic theory. One, as a thinker of participative democracy, in his actionist period - when he was a member of the Party of Action, in the forties of the last century; the other, as a thinker of democratic proceduralism, since the middle of the fifties. Each of those particular forms of democratic regime conceptions inserts itself in different traditions. This article intents to situate those traditions and the particular way that Bobbio's conceptions cross with them.

Keywords: Norberto Bobbio; Democratic traditions; Ethical democracy; Procedural democracy. 